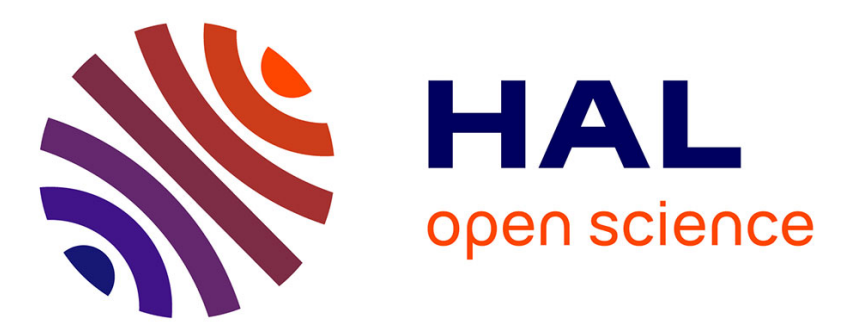

\title{
International cooperation on western corn rootworm ecology research: state-of-the-art and future research
}

J. Moeser, Thomas T. Guillemaud

\section{To cite this version:}

J. Moeser, Thomas T. Guillemaud. International cooperation on western corn rootworm ecology research: state-of-the-art and future research. Agricultural and Forest Entomology, 2009, 11 (1), pp.3-7. 10.1111/j.1461-9563.2008.00404.x . hal-02668204

\section{HAL Id: hal-02668204 \\ https://hal.inrae.fr/hal-02668204}

Submitted on 15 Sep 2020

HAL is a multi-disciplinary open access archive for the deposit and dissemination of scientific research documents, whether they are published or not. The documents may come from teaching and research institutions in France or abroad, or from public or private research centers.
L'archive ouverte pluridisciplinaire HAL, est destinée au dépôt et à la diffusion de documents scientifiques de niveau recherche, publiés ou non, émanant des établissements d'enseignement et de recherche français ou étrangers, des laboratoires publics ou privés. 


\title{
International cooperation on western corn rootworm ecology research: state-of-the-art and future research
}

\author{
J. Moeser and T. Guillemaud* \\ Agricultural Entomology, DNPW, Georg-August-University Goettingen, Grisebachstrasse 6, 37077 Goettingen, Germany and \\ *Equipe 'Biologie des Populations en Interaction', UMR 1112 R.O.S.E. INRA-Université de Nice-Sophia Antipolis, 400 Route des Chappes, \\ BP 167-06903 Sophia Antipolis, Cedex, France
}

\begin{abstract}
Invasive pest species are challenging partly because the invasion process may be highly dynamic and because of the lack of knowledge of many researchers, professionals and farmers in the newly-invaded regions. The chrysomelid Diabrotica virgifera virgifera LeConte is such an invasive pest. It has been the main pest of continuous maize in the U.S.A. for more than 60 years and is currently spreading throughout Europe.

2 In the area with a long history of this pest (Central and North America), scientific knowledge concerning the ecology of this pest has accumulated over the last decades. This resource is of great importance to both America and Europe and has to be gathered, shared and adapted to new situations. We therefore examined, both qualitatively and quantitatively, the scientific literature relating to D. virgifera virgifera ecology.

3 The quantitative analysis suggests that research on D. virgifera virgifera ecology is still in its infancy in Europe and suffers from geographical barriers (between Europe and North America and between linguistic areas within Europe) and that scientific communication should be strengthened both between North America and Europe and within Europe.

4 As a first solution to this problem, we introduce three companion review articles that constitute a landmark for D. virgifera virgifera research, enabling European and American scientists and decision-makers to orient themselves and discover new opportunities for research. We also stress that international research cooperation is the most important key to successfully manage invasive species.
\end{abstract}

Keywords Adaptation during invasion process, adaptation to management practices, behavioural ecology, Diabrotica virgifera virgifera, invasive species, population dynamics, genetic tools.

\section{Introduction}

An understanding of the intimate relationships between a pest and its biotic and abiotic environment is essential for the design of efficient eradication, containment and management strategies (Myers et al., 1998; Thomas et al., 2000; Carrière et al., 2003). Such an understanding forms the basis of integrated pest management (IPM) practices. IPM research remains a high priority, with more than $\$ 170$ million being requested in the 2008 budget of the U.S. Department of

Correspondence: Joachim Moeser. Tel.: +49 551393733; fax: +49 5513912105; e-mail: jmoeser@gwdg.de
Agriculture, Agricultural Research Service for the study of diseases and pests for crop protection (Anonymous, 2008).

We face a particular challenge in IPM when the environment of a pest changes favourably with regard to the pest's requirements (e.g. the development of intensive agriculture and the emergence of the Corn Belt in the U.S.A. over the last 70 years has increased the availability of food for pests) or when a pest moves into a new, favourable environment (e.g. biological invasions). The key to managing an invasive pest with a dramatic increase in distribution, if it cannot be eradicated, lies in an understanding of the details of its ecology (Simberloff, 2003). Invasive pest species are challenging for at least four reasons. First, the successful invasion of new geographic 
areas illustrates their capability to evolve and to adapt to new conditions. Second, the invasion process is often highly dynamic, with a long post-introduction lag during which the pest remains at low density, followed by an abrupt, rapid increase in population size. Third, the genetic architecture of invading species is often profoundly reshaped. Finally, the invasion itself presents a challenge because many researchers, decisionmakers, professionals and farmers in the newly-invaded regions lack basic ecological knowledge about the invading species.

\section{The invasion of Europe by western corn rootworm (WCR)}

The maize root-feeding chrysomelid Diabrotica virgifera virgifera LeConte (Coleoptera, Chrysomelidae) known as the western corn rootworm in North America, has invaded Europe and is currently spreading across the continent. In the U.S.A., half a century of practical experience and scientific research concerning this pest has accumulated. This tremendous resource is of great importance to Europe for several reasons.

First, publications on WCR ecology cover more than half a century of scientific work, mainly in the U.S.A., because WCR was recognized as a major pest of maize during the middle of the 20th Century (Luckmann et al., 1974) and it is currently the main pest of continuous maize crops in the U.S.A. (Sappington et al., 2006). The feeding by larvae of WCR weaken the root system of maize plants. This renders the plants more susceptible to drought and disease and prone to lodging, making it difficult to harvest the crop. Sappington et al. (2006) reported estimated control costs and yield losses amounting to more than $\$ 1$ billion per annum in the U.S.A. WCR has recently arrived in Europe and is now the main pest of continuous maize crops in Central and South-Eastern Europe. The cost of WCR to European agriculture is estimated to exceed $€ 147$ million per year in terms of pecuniary losses alone in just seven selected Western European countries, based on the maize production area at the end of the 1990s (Baufeld \& Enzian, 2005).

Second, the European agricultural environment is likely to change such that the area under maize is increased. Rapid growth in demand for renewable energy sources fuelled by maize will lead to more areas being planted continuously with maize over long periods and over large areas in the future (Odling-Smee, 2007). As this happens, we can assume that potential losses to WCR will increase as increasing amounts of maize are grown continuously on the same fields each year for bioenergy production. Continuous maize cropping, with no rotation, provides ideal conditions for an increase in WCR population size, if not properly managed. The dedication of larger areas to maize production will certainly present a challenge to plant protection services and academic researchers trying to develop strategies for the sustainable management of WCR, at the same time as decreasing the environmental impact of various control option, for example, insecticide use (Hill et al., 2006).

Third, in North America, WCR has a long history of adaptation to several management practices. Historically, WCR has been managed by crop rotation (maize and another crop, such as soybean, are grown alternating each year) and chemi- cal insecticide treatments. WCR has clearly adapted to these management practices. The insect has developed resistance to the chlorinated hydrocarbon insecticides and to methylparathion (Ball \& Weekman, 1963; Stebbing et al., 2005) and is now adapting to crop rotation. A crop rotation-adapted variant WCR appeared around the mid 1990s and continues to spread throughout the U.S. Corn Belt (Gray et al., 1998). These adaptations renewed the interest in research on this pest. New research into the genetics of this pest has been initiated in the U.S.A. and Europe and is required if we are to understand the basis of potential adaptations in terms of feeding, oviposition and migration behaviour. For example, our understanding of the origin, mechanism and spread throughout the Corn Belt of the crop rotation adaptation may greatly benefit from knowledge acquired in population genetics, quantitative genetics and classical formal genetics studies of these behavioural traits (Miller et al., 2006). The recent use in the U.S.A. of insecticidal bacterial toxins incorporated into GM maize should be considered a temporary solution. Indeed, given the history of adaptation of WCR, the development of Bt-maize resistance in this pest is a justifiable concern (Onstad et al., 2001).

Finally, WCR, originally an American pest, has invaded a new area in the early 1990s: Europe. First observed near Belgrade Airport in the former Yugoslavia in 1992 (Baca, 1994), it is believed to have been introduced into Europe in the late 1980s or early 1990s. It has subsequently spread throughout a large part of South-Eastern Europe and has been observed in several countries in Western Europe (Kiss et al., 2005). The agricultural situation in the EU is believed to be very different from that in the American Corn Belt in terms of average field size, crop rotation practices and pesticide use and regulations. These differences are likely to affect the ecological characteristics of WCR, potentially resulting in behavioural adaptation to the insect's new range (shorter dispersion, modified diet, change of oviposition site preference, etc.). Potential changes in the ecological characteristics of WCR may also result from major changes in population genetic structure occurring during the introduction of this pest into Europe (Miller et al., 2005). Indeed, population genetic variability and architecture (e.g. decrease in heterozygosity, change in the epistatic component of genetic variance) may be highly sensitive to demographic bottlenecks during early stages of the invasion (Lee, 2002).

\section{Analysis of gaps in international research cooperation}

If we are to benefit from the knowledge accumulated on this invasive species over a number of years in its former distribution range, we need to gather this knowledge, share it and adapt it to new situations. Gathering state-of-the art knowledge from the U.S.A. and from as many European research groups as possible is also crucial to avoid the duplication of research efforts by different European groups. During March 2007 in Nice (France), an international workshop on WCR Ecology was set up to obtain this information within the European Sixth Framework Programme and the Specific Support Action 'DIABR-ACT: Harmonise the strategies for 
fighting Diabrotica virgifera virgifera' (SSPE-CT- 2006022623). The participating scientists: (i) reported on state-ofthe-art knowledge about this pest and (ii) identified knowledge gaps potentially crucial for future management decisions.

The Illinois Natural History Survey maintains a database of scientific references on WCR published until 1988 (Luckmann et al., 1974; Irwin, 1977; Levine \& Chan, 1990). When research on WCR began in Europe, this research area was dominated from the outset by a highly diverse and fragmented set of scientists isolated from each other and from American scientists. This led us to examine, qualitatively and quantitatively, European scientific output relating to WCR and to compare it with that of the U.S.A. We thus collected bibliographical data from the Web of Science (1992-2006) and the CAB abstract (1973-2006) using the keywords 'WCR', 'western corn rootworm' and 'Diabrotica virgifera'. After removing references unrelated to the subject, we ended up with a database containing 766 papers written by 974 authors. An analysis of the co-authorship network (i.e. who publishes with whom) was performed using this database to examine possible structure within the scientific community and to identify the underlying reasons for it. Only authors who had published more than one paper were included in the network analysis. The connected components of the graph were identified and their size was measured using the clusters function of the $\mathrm{R}$ igraph package (Csardi, 2006; R Development Core Team, 2006). The co-authorship tree was built from the largest independent component of the graph (268 authors and 588 papers) with the clustering algorithm proposed by Girvan and Newman (2002). A multi-response permutation procedure (Mielke, 2001) was used to test whether the authors were significantly more similar within than between the clusters defined by the nodes of the tree. The similarity statistic used was the weighted within-group mean of pairwise dissimilarities between elements. As described by Prado and Lewinsohn (2004), dissimilarity was calculated as a Jaccard distance and group size was used as the group weight. The permutation algorithm is included in the multi-response permutation procedure function of the $\mathrm{R}$ vegan package (Oksanen et al., 2006; R Development Core Team, 2006).

The co-authorship network proved to be highly and significantly structured (multi-response permutation procedure test, $P<0.001)$. Figure 1 shows that the main structure of the tree correlates strongly with the geographical location of the corresponding author's affiliation. North American scientists tend to publish more with North Americans than with anyone else and Europeans tend to publish more with Europeans than with anyone else (Fig. 1). Only $7 \%$ of the authors in the hierarchical tree of Fig. 1 are misclassified on the basis of geographical location. This suggests that European and American scientists may not be cooperating sufficiently. We carried out a more detailed analysis of publication as a function of geographical location. In the past, European scientists from 22 countries published 181 papers in 17 different languages, with approximately half (94) published in English compared with $99 \%$ for the North American papers. This includes an unknown percentage of publications in journals that are not peer-reviewed. Thus, much of the informa-

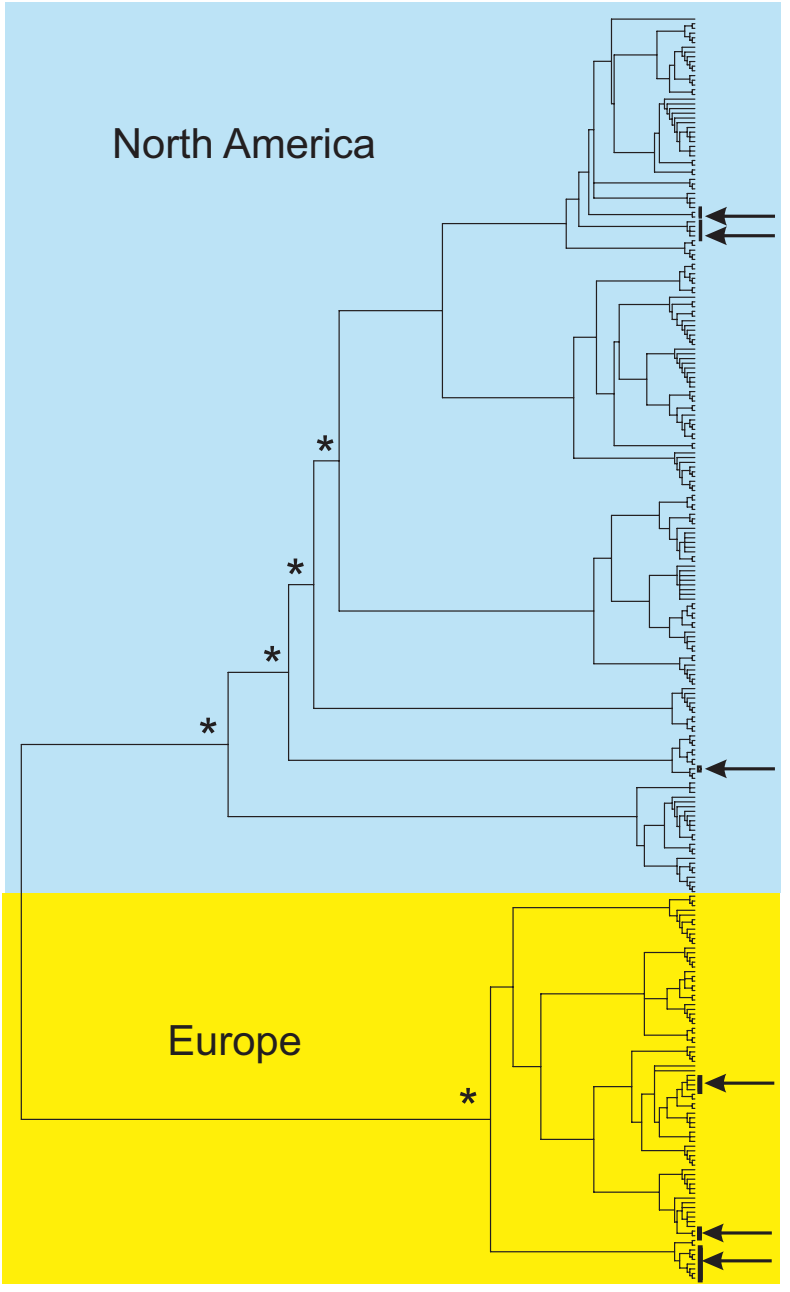

Figure 1 Hierarchical tree showing the structure of the authorship network. The arrows indicate outlier authors (i.e. authors whose geographical location is not consistent with the geographical clustering of the hierarchical tree). For space constraints, only the tree leaves corresponding to authors were kept. A star above a node indicates that the authors are significantly more similar within than between the clusters defined by the nodes.

tion generated by research in Europe may not be comprehensible to scientists elsewhere due to linguistic differences. This finding identifies an additional condition for a scientific community to benefit from the knowledge already present about an invasive pest; the area of origin of the pest must display an organized scientific field, in which knowledge is practically available. A situation in which an invasive pest originated from Eurasia and invaded North America [as the European Corn Borer, Ostrinia nubilalis (Hübner)] may be worse than an invasion in the opposite direction, partly due to such linguistic problems. Our bibliographic analysis shows that a European scientific community working on WCR is emerging. Most European papers in the database were published recently ( $98 \%$ after the first observation of WCR in Europe) and the publication rate has increased, with more than half of the papers (99) being published after 2003 
(versus $15 \%$ for North America). Finally, significantly more European papers than American papers were published in journals with no impact factor $(88 \%$ versus $15 \%$, Fisher's exact test, $P<0.0001)$. Together with linguistic problems, this finding demonstrates that most of the European papers in the database are probably read exclusively by local professionals (farmers and decision-makers) rather than by scientists. These results suggest that ecological research on WCR ecology is still in its infancy in Europe and suffers from geographical barriers (between Europe and North America and between linguistic areas within Europe) and that scientific communication should be strengthened both between North America and Europe and within Europe.

\section{Gathering the knowledge in WCR ecology}

The three reviews that follow constitute a landmark for WCR research, enabling European and American scientists and decision-makers to orient themselves and discover new opportunities for research. Recently established research groups such as the Diabrotica Genetics Consortium (Sappington et al., 2006) have led the way towards new transatlantic research activities.

These reviews will cover three main topics with regard to WCR ecology. The first deals with the behaviour of WCR adults and larvae, focusing in particular on feeding and oviposition behaviour, small/large-scale movement related to flight behaviour and within-plant distribution (microscale distribution) (Spencer, et al., 2009). The second review deals with WCR population dynamics. It examines diapause, larval and adult dynamics, within- and between-field (spatial) distribution, long-distance movement related to population dynamics and the dynamics of spread in North America and Europe (Meinke, et al., 2009). A huge amount of genetic data has been accumulated after the last comprehensive WCR review published in a peer-reviewed journal (Chiang, 1973). For this reason, the third review concerns the genetics and adaptations of WCR (Miller, et al., 2009). This paper includes a description of molecular tools and newly emerging genomic resources. It also presents their applications, focusing in particular on descriptions of the evolution of recent adaptive characters (resistance to crop rotation and insecticides) and of routes of introduction into Europe.

\section{Acknowledgements}

This work was funded by the European Union, as part of the DIABR-ACT project: 'Harmonise the strategies for fighting Diabrotica virgifera virgifera' (SSPE-CT- 2006-022623). We thank Corinne Vacher for helpful discussions about network clustering.

\section{References}

Anonymous (2008) USDA. FY 2008. Budget Summary and Annual Performance Plan. U.S. Department of Agriculture, Washington D.C.
Baca, F. (1994) New member of the harmful entomofauna of Yugoslavia Diabrotica virgifera virgifera LeConte (Coleoptera, Chrysomelidae). Zastita Bilja, 45, 125-131.

Ball, H.J. \& Weekman, G.T. (1963) Differential resistance of corn rootworms to insecticides in Nebraska and adjoining states. Journal of Economic Entomology, 56, 553-555.

Baufeld, P. \& Enzian, S. (2005) Maize growing, maize high-risk areas and potential yield losses due to western corn rootworm (Diabrotica virgifera virgifera) damage in selected European countries. Western Corn Rootworm: Ecology and Management (ed. by S. Vidal, U. Kuhlmann and C. R. Edwards), pp. 285-302. CABI Publishing, U.K.

Carrière, Y., Ellers-Kirk, C., Sisterson, M., Antilla, L., Whitlow, M., Dennehy, T.J. \& Tabashnik, B.E. (2003) Long-term regional suppression of pink bollworm by Bacillus thuringiensis cotton. Proceedings of the National Academy of Sciences of the United States of America, 100, 1519-1523.

Chiang, H.C. (1973) Bionomics of the northern and western corn rootworms. Annual Review of Entomology, 18, 47-72.

Csárdi, G. \& Nepusz, T. (2006) The igraph software package for complex network research. InterJournal Complex Systems, 1695 [WWW document]. URL http://necsi.org/events/iccs6/papers/c16 02a3c126ba822d0bc4293371c.pdf [accessed for online publication 2006].

Girvan, M. \& Newman, M.E.J. (2002) Community structure in social and biological networks. Proceedings of the National Academy of Science of the United States of America, 99, 78217826.

Gray, M.E., Levine, E. \& Oloumi-Sadeghi, H. (1998) Adaptation to crop rotation: western and northern corn rootworms respond uniquely to a cultural practice. Recent Research and Developments in Entomology, 2, 19-31.

Hill, J., Nelson, E., Tilman, D., Polasky, S. \& Tiffany, D. (2006) Environmental, economic, and energetic costs and benefits of biodiesel and ethanol biofuels. Proceedings of the National Academy of Sciences of the United States of America, 103, 11206-11210.

Irwin, B.J. (1977) A Bibliography of the Northern Corn Rootworm and the Western Corn Rootworm: An Updating through 1976. Biological Notes No. 101. Illinois Natural History Survey, UrbanaChampaign, Illinois.

Kiss, J., Edwards, C.R., Berger, H.K. et al. (2005). Monitoring of western corn rootworm (Diabrotica virgifera virgifera LeConte) in Europe 1992-2003. Western Corn Rootworm: Ecology and Management (ed. by S. Vidal, U. Kuhlmann and C. R. Edwards), pp. 29-39. CABI Publishing, CAB International, Wallingford, U.K.

Lee, C.E. (2002) Evolutionary genetics of invasive species. Trends in Ecology and Evolution, 17, 386-391.

Levine, E. \& Chan, S.Y. (1990) A Bibliography of the Northern and Western Corn Rootworm: An Update 1977 through 1988. Biological Notes No. 135. Illinois Natural History Survey, UrbanaChampaign, Illinois.

Luckmann, W.H., Chiang, H.C., Ortman, E.E. \& Nichols, M.P. (1974) A Bibliography of the Northern Corn Rootworm, Diabrotica longicornis (Say), and the Western Corn Rootworm, Diabrotica virgifera LeConte (Coleoptera: Chrysomelidae). Biological Notes No. 90. Illinois Natural History Survey, Urbana-Champaign, Illinois.

Mielke, P.W. \& Berry, K.J. (2001) Permutation Methods: A Distance Function Approach. Springer-Verlag, New York, New York.

Meinke, L., Sappington, T.M., Onstad, D. et al. (2009) Western corn rootworm (Diabrotica virgifera virgifera LeConte) population dynamics. Agriculture and Forest Entomology, 11, $29-46$.

Miller, N., Estoup, A., Toepfer, S. et al. (2005) Multiple transatlantic introductions of the western corn rootworm. Science, 310, 992. 
Miller, N., Kim, K.S., Ratcliffe, S.T., Estoup, A., Bourguet, D. \& Guillemaud, T. (2006) Absence of genetic divergence between western corn rootworms resistant or susceptible to control by crop rotation. Journal of Economic Entomology, 99, 685-690.

Miller, N.J., Guillemaud, T., Giordano, R. et al. (2009) Genes, gene flow and adaptation of Diabrotica virgifera virgifera. Agriculture and Forest Entomology, 11, 47-60.

Myers, J.H., Savoie, A. \& Randen, E. (1998) Eradication and pest management. Annual Reviews of Entomology, 43, 471-491.

Odling-Smee, L. (2007) Biofuels bandwagon hits a rut. Nature, 446, 483.

Oksanen, J., Kindt, R., Legendre, P. \& O'Hara, R.B. (2006) Vegan: Community Ecology Package version 1.8.3 [WWW document]. URL http://cc.oulu.fi/ jarioksa/

Onstad, D.W., Guse, C.A., Spencer, J.L., Levine, E. \& Gray, M.E. (2001) Modeling the dynamics of adaptation to transgenic corn by western corn rootworm (Coleoptera: Chrysomelidae). Journal of Economic Entomology, 94, 529-540.

Prado, P.I. \& Lewinsohn, T.M. (2004) Compartments in insect-plant associations and their consequences for community structure. Journal of Animal Ecology, 73, 1168-1178.
R Development Core Team (2006) R: A Language and Environment for Statistical Computing [WWW document]. URL http://www. R-project.org

Sappington, T.W., Siegfried, B.D. \& Guillemaud, T. (2006) Coordinated Diabrotica genetics research: accelerating progress on an urgent insect pest problem. American Entomologist, 52, 90-97.

Simberloff, D. (2003) How much information on population biology is needed to manage introduced species. Conservation Biology, 17, 83-92.

Spencer, J.L., Hibbard, B.E. Moeser, M., Onstad, D. (2009) Behaviour and ecology of the western corn rootworm (Diabrotica virgifera virgifera LeConte). Agriculture and Forest Entomology, 11, 9-27.

Stebbing, J.A., Meinke, L.J., Naranjo, S.E., Siegfried, B.D., Wright, R.J. \& Chandler, L.D. (2005) Flight behaviour of methyl-parathionresistant and -susceptible western corn rootworm (Coleoptera: Chrysomelidae) Populations from Nebraska. Journal of Economic Entomology, 98, 1294-1304.

Thomas, D.D., Donnelly, C.A., Wood, R.J. \& Alphey, L.S. (2000) Insect population control using a dominant, repressible, lethal genetic system. Science, 287, 2474-2476. 